\title{
Morphological configuration of the cranial base among children aged 8 to 12 years
}

\author{
Lina Cossio, Jorge López, Zulma Vanessa Rueda and Paola Botero-Mariaca*
}

\begin{abstract}
Background: Cranial base is used as reference structure to determine the skeletal type in cephalometric analysis. The purpose was to assess the cranial base length on lateral cephalic radiographs of children between 8 and 12 and compare these measurements with baseline studies in order to evaluate the relationship between the length and the cranial base angle, articular angle, gonial angle and skeletal type.

Methods: A Cross-sectional study in 149 children aged 8-12 years, originally from Aburrá Valley, who had lateral cephalic radiographs and consented to participate in this study. The variables studied included: age, sex, sella-nasion, sella-nasion-articular, sella-nasion-basion, articular-gonion-menton, gonion-menton, sella-nasion-point B, sellanasion-point A y point A-nasion-point B. These variables were digitally measured through i-dixel 2 digital software. One-way ANOVA was used to determine mean values and mean value differences. The values obtained were compared with previous studies. A p value $<0.05$ was considered significant.
\end{abstract}

Results: Cranial base lengths are smaller in each age and sex group, with differences exceeding $10 \mathrm{~mm}$ for measurement, compared both with the study by Riolo (Michigan) and the study carried out in Damasco (Antioquia). No relation was found between the skeletal type and the anterior cranial base length, the sella angle and the cranial base angle. Also, no relation was found between the gonial angle and sella angle or the cranial base angle.

Conclusion: The cranial base varies from one population to another. Accordingly, compared to other studies it is shorter for the assessed sample.

Keywords: Cranial base, Growth, Length, Mean values

\section{Background}

The anterior cranial base (sella-nasion) is an important component of the craniofacial structure because it influences both its dimension and growth orientation. It also serves as a reference to determine the size of both the maxilla and the mandible in lateral cephalic radiographs. Since it is considered stable, this structure is the basis for skeletal diagnose. Its linear size as well as the angle formed with the posterior cranial base (sella-basion) has been classified for certain populations as mean values by age for each sex [1]. Furthermore, a relation either positive or negative between the length and angulation of the

*Correspondence: paola.botero@campusucc.edu.co; pboterom@gmail.com

Universidad Cooperativa de Colombia, Carrera 47 \# 37 South 18 Medellín, Antioquia, Colombia cranial base and both the sagittal skeletal type and vertical growth has been reported by different studies [1].

In a cephalometric analysis three types of skeletal anteroposterior relationships can be diagnosed, type I relationship when the maxilla and mandible have normal anteroposterior position (Average ANB), type II relationship when the mandible is positioned distally to the maxilla (larger ANB than average) and type III when mandible is mesially positioned to the maxilla (decreased ANB than average) (Figs. 1, 2).

The anterior cranial base may have different mean values for sizes according to the population where the study is carried out. For example, Bolton in Ohio and Riolo in Michigan found significant differences when comparing the length of the sella-nasion plane [2, 3]. Several studies have been carried out in Colombia, but these results have not yet been taken into account to implement applicable 


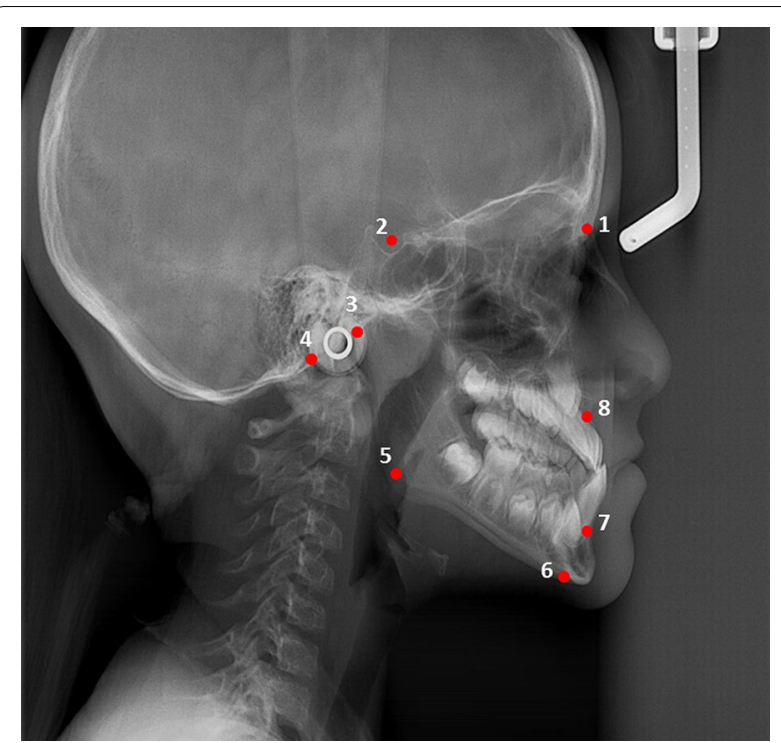

Fig. 1 Location of reference points for lateral cephalic radiograph obtained for this study. 1 Nasion (N): junction of nasal and frontal bones. 2 Sella (S): midpoint of sella turcica. 3 Articular (Ar): point of intersection of the basilar apophysis of the occipital bone and the posterior border of the condyle. 4 Basion (Ba): most anterior inferior point of the anterior border of the occipital hole. 5 Gonion (Go): determined at the bisection of the angle formed by the posterior surface of the mandibular ramus and the mandibular body. 6 Menton (Me): lower most point of the mandibular symphysis curve. $7 \mathrm{~B}$ point (B): deepest point on anterior profile of mandibular symphysis. $8 \mathrm{~A}$ point (A): deepest point on anterior profile of superior maxilla

mean values for our population. The reasons for this are: sample size, type of methodology used, as well as variation among X-ray equipment. Some of these studies include Zagarra and Villegas in Bogotá [4], Cárdenas in Heliconia (Antioquia) [5], Palacino in Medellín [6] and Botero et al. in Damasco, Antioquia [7].

Cranial base length and flexure influences jaw relationship, glenoid fossa sagittal position among others. A decreased basicranial angulation has been related with type III mandibular position. Steeper posterior cranial base, more inferiorly positioned sphenoidale and more anteriorly positioned basion are major characteristics of type III [8-11]. In cephalometric analysis the determination of skeletal relationships between maxilla and mandible are established using cranial base as a reference structure. Cranial base growth and development can have a genetic influence and therefore have a specific configuration depending upon the genetic ancestry. Cranial base length in individuals form Aburra Valley is different from previous studies, given the variability between growth patterns in different populations. The aim of this study was to assess the cranial base length on lateral cephalic radiographs of children aged between $8-12$ in order to compare them with other baseline studies and evaluate the relation between the length and the cranial base angle, the articular angle, the gonial angle and the skeletal type based on the ANB angle.

\section{Methods \\ Type of study}

Cross-sectional.

\section{Population}

Children aged 8-12 who were scheduled for lateral cephalic radiographs. The sample collection was carried out in a radiology center of the city. The sample was collected and measured from February 29, 2012, to April 25,2013 . While the researchers of the present study did not prescribe the radiographs, written informed consent was obtained from all parents or legal guardians to assess their radiographs. This study is in compliance with the ethical requirements provided by Resolution 8430 of 1993, issued by the Ministry of Health of Colombia, and was approved by the Ethics Committee of the Universidad Cooperativa de Colombia, Medellín.

\section{Sample size}

It was calculated based on the mean values and standard deviations for the sella-nasion obtained for every age and sex range, from the studies by Riolo in Michigan [3] and Botero et al. in Damasco, Antioquia [7]. With a confidence level of $95 \%$, an estimated loss of information of $20 \%$ and accuracy level of $2 \%$, a sample of 148 patients was obtained, according to the data of the study carried out by Riolo, and 58 patients according to the study by Botero et al. The higher size was taken for this study. Estimation of sample size was done with the EPIDAT 3.1 software, which yielded a sample size of 149 radiographs.

\section{Inclusion criteria}

Boys and girls aged 8-12 who attended the radiology center of the dental school at Universidad Cooperativa de Colombia, in order to get a lateral cephalic radiograph taken; who agreed to take art in the study and were born in the Aburrá Valley.

\section{Exclusion criteria}

Patients with syndromes involving craniofacial structures, black race patients and lateral cephalic radiographs with structures that rendered location of cephalometric points impossible.

\section{Procedures}

The lateral cephalic radiographs were obtained with MORITA Veraviewepocs 2D, with an exposure time 

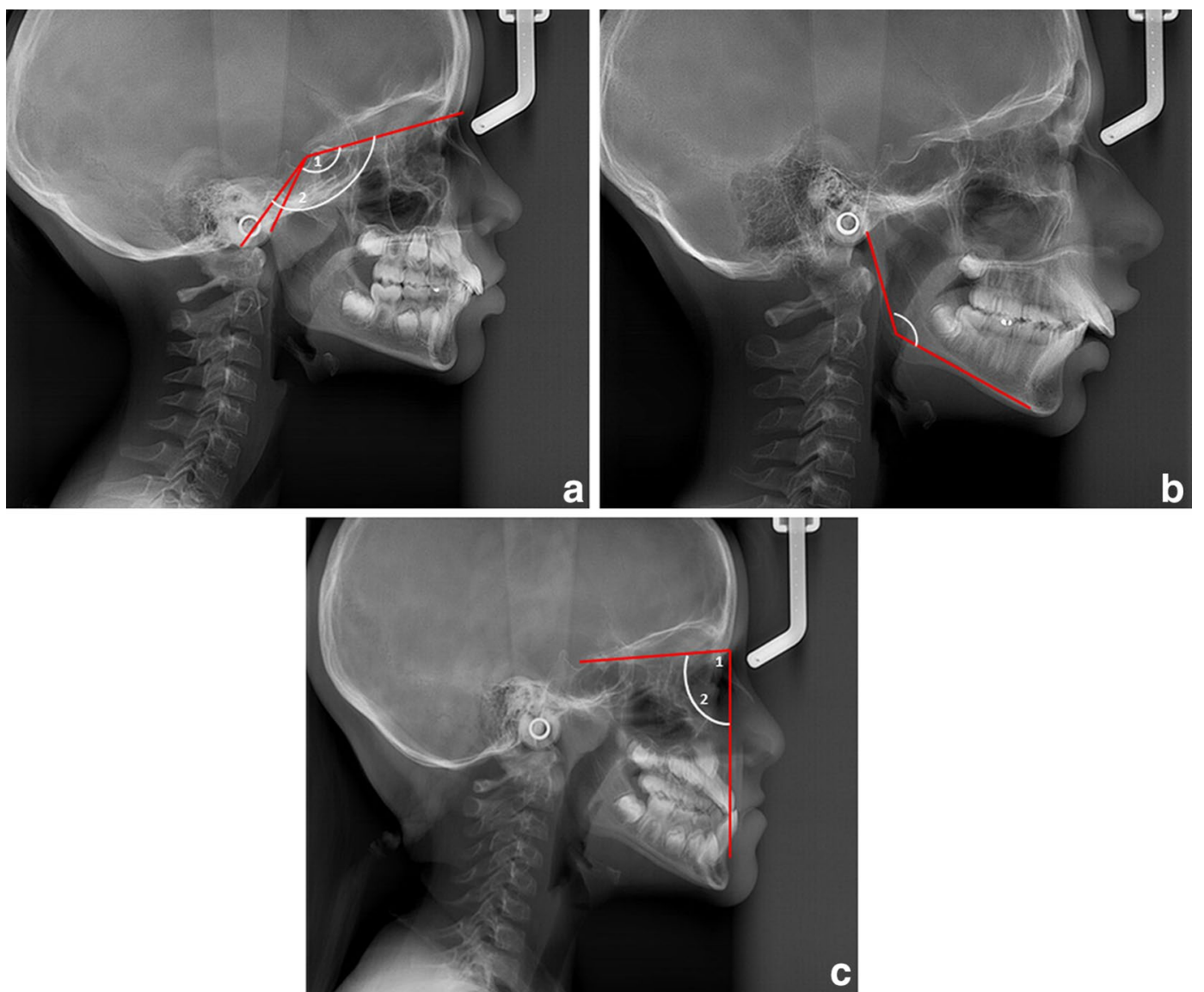

Fig. 2 a Type I patient: 1 Measurement S-N-Ba angle. 2 Measurement S-N-Ar angle. b Type II patient: Measurement Ar-Go-Me angle. c Type III patient: 1 Measurement SNA angle. 2 Measurement SNB angle

of approximately $4.9 \mathrm{~s}$ and a constant magnification of $10.9 \%$. For measurements, i-Dixel software was used. A bone filter was applied for improved contrast and more accurate location of structures.

\section{Variables}

The following were the cephalometric measurements assessed: Sella-nasion (S-N), Sella-nasion-basion (S-NBa), Sella-nasion-articular (S-N-Ar), Sella-nasion-A point (SNA), Sella-nasion-B point (SNB), Articular-gonionmenton (Ar-Go-Me) vertical rotation and ANB angle. Outcomes: type I when $\mathrm{AB}$ is average, type II when ANB is larger, type III when ANB is decreased. Neutral rotation when $\mathrm{Ar}-\mathrm{Go}-\mathrm{Me}$ is coincident with average, Ar-Go-Me larger than the average shows vertical rotation and Ar-GoMe reduced is a horizontal rotation.

\section{Statistical analysis}

Only one researcher performed the measurements in order to avoid variations from one person to another.
Prior to the start of the study, radiograph readings were standardized between one of the expert researchers and the researcher responsible for the measurements. Interobserver concordance was assessed for each of the cephalometric measurements above, by using the intraclass correlation coefficient with mixed effects.

All cephalometric variables showed normal distribution. Therefore, the results are reported as mean values and standard deviations, stratified by age and gender. Subsequently, mean differences were tested through Student $t$ test, in order to compare the values obtained in the present study with those obtained by Riolo in Michigan [3] and Botero et al. [7] in Damasco, Antioquia. Finally, one-way ANOVA tests were used to compare mean values of the cranial base length $(\mathrm{S}-\mathrm{N})$, the articular angle (Ar-Go-Me), and the S-Na-Ba angle with the ANB skeletal type (I, II, III) and the gonial angle (neutral, horizontal and vertical). The significance level was 0.05 . The database was processed in $\mathrm{Excel}^{\circledR}$, while the data analysis was performed through SPSS 20.0. 


\section{Results}

The interobserver concordance value for cephalometric measurements for standardization was higher than 0.8 for each of the variables (S-N: 0.99, S-N-Ar: 0.96, S-N-Ba, 0.92, SNA: 0.95, SNB: 0.91, Go-Me: 0.82, y Ar-Go-Me: 0.87), indicating almost perfect concordance. Consequently, the measurements performed were reliable.

Table 1 Children included in the study by gender and age

\begin{tabular}{lccc}
\hline Age & Male & Female & Total \\
\hline 8 & 16 & 16 & 32 \\
9 & 20 & 20 & 40 \\
10 & 18 & 22 & 40 \\
11 & 14 & 10 & 24 \\
12 & 6 & 7 & 13 \\
Total & 74 & 75 & 149 \\
\hline
\end{tabular}

A total of 149 children were included of those who went to the radiology center and met the inclusion criteria. Gender distribution was similar for each age range (Table 1 ).

The mean value for the cranial base was significantly lower across all age and gender groups of the present study, compared to the research by Riolo [3]. Also, the sella-nasion angle was wider among 11 year-old boys, while the sella-nasion-articular angle was wider among 10 and 11 year-old boys (Table 2).

When comparing the results with the study by Botero et al. [7], all measurements for anterior cranial base obtained in the present study were observed to be significantly lower than those reported by the aforementioned authors (Table 3).

Nine children out of 149 were classified as skeletal type I, $66.7 \%$ of these exhibited a normal skull base angle, $21.1 \%$ exhibited an increased angle and only $12.2 \%$ exhibited a decreased angle. Twenty-five children were

Table 2 Comparison of sella-nasion, sella-nasion-basion and sella-nasion-articular measurements of this study and the research by Riolo [3]

\begin{tabular}{|c|c|c|c|c|c|c|c|c|c|c|c|}
\hline \multirow[t]{3}{*}{ Measurements } & \multicolumn{5}{|c|}{ Current study } & \multicolumn{4}{|l|}{ Riolo } & \multirow{2}{*}{\multicolumn{2}{|c|}{ p value }} \\
\hline & \multirow[t]{2}{*}{ Age (years) } & \multicolumn{2}{|l|}{ Female } & \multicolumn{2}{|l|}{ Male } & \multicolumn{2}{|l|}{ Female } & \multicolumn{2}{|l|}{ Male } & & \\
\hline & & Mean value & SD & Mean value & SD & Mean value & SD & Mean value & SD & Female & Male \\
\hline \multirow[t]{5}{*}{ Sella nasion } & 8 & 60.23 & 2.8 & 60.91 & 2.11 & 72.3 & 2.9 & 75.2 & 3.0 & $<0.001$ & $<0.001$ \\
\hline & 9 & 60.57 & 2.7 & 62.48 & 2.0 & 72.6 & 2.7 & 75.9 & 3.3 & $<0.001$ & $<0.001$ \\
\hline & 10 & 62.22 & 2.2 & 64.22 & 2.0 & 73.9 & 2.8 & 76.8 & 3.2 & $<0.001$ & $<0.001$ \\
\hline & 11 & 62.38 & 3.7 & 62.11 & 2.4 & 74.3 & 3.0 & 78.2 & 2.9 & $<0.001$ & $<0.001$ \\
\hline & 12 & 63.54 & 3.0 & 64.27 & 1.4 & 74.9 & 3.0 & 78.3 & 3.3 & $<0.001$ & $<0.001$ \\
\hline \multirow[t]{5}{*}{ Sella nasion/basion } & 8 & 133.36 & 7.57 & 130.46 & 5.15 & 130.0 & 4.8 & 129.0 & 4.8 & 0.117 & 0.311 \\
\hline & 9 & 130.96 & 4.9 & 129.25 & 5.21 & 129.8 & 4.6 & 129.6 & 4.6 & 0.39 & 0.785 \\
\hline & 10 & 131.19 & 4.45 & 130.99 & 4.13 & 129.7 & 4.5 & 129.2 & 4.7 & 0.22 & 0.162 \\
\hline & 11 & 128.22 & 3.76 & 132.94 & 4.92 & 129.9 & 4.8 & 128.9 & 4.8 & 0.32 & 0.009 \\
\hline & 12 & 130.07 & 6.2 & 132.20 & 4.76 & 130.4 & 5.2 & 129.3 & 4.8 & 0.88 & 0.171 \\
\hline \multirow[t]{5}{*}{ Sella nasion/articular } & 8 & 124.52 & 4.26 & 124.28 & 4.62 & $123^{\circ}$ & 5 & $123^{\circ}$ & 5 & 0.31 & 0.296 \\
\hline & 9 & 125.18 & 5.43 & 124.13 & 7.0 & $123^{\circ}$ & 5 & $123^{\circ}$ & 5 & 0.14 & 0.457 \\
\hline & 10 & 125.16 & 5.7 & 126.03 & 5.2 & $123^{\circ}$ & 5 & $123^{\circ}$ & 5 & 0.13 & 0.035 \\
\hline & 11 & 122.9 & 4.2 & 128.72 & 4.0 & $123^{\circ}$ & 5 & $123^{\circ}$ & 5 & 0.95 & 0.0003 \\
\hline & 12 & 124.40 & 6.6 & 126.04 & 4.11 & $123^{\circ}$ & 5 & $123^{\circ}$ & 5 & 0.54 & 0.162 \\
\hline
\end{tabular}

Table 3 Sella-nasion comparison: between this study and the study by Botero et al. [7]

\begin{tabular}{|c|c|c|c|c|c|c|c|c|c|c|c|}
\hline \multirow[t]{3}{*}{ Measurements } & \multicolumn{5}{|c|}{ Current study } & \multicolumn{4}{|l|}{ Botero et al. } & \multirow{2}{*}{\multicolumn{2}{|c|}{ p value }} \\
\hline & \multirow[t]{2}{*}{ Age (years) } & \multicolumn{2}{|l|}{ Female } & \multicolumn{2}{|l|}{ Male } & \multicolumn{2}{|l|}{ Female } & \multicolumn{2}{|l|}{ Male } & & \\
\hline & & Mean value & SD & Mean value & SD & Mean value & SD & Mean value & SD & Female & Male \\
\hline \multirow[t]{3}{*}{ Sella-nasion } & 8 & 60.23 & 2.8 & 60.91 & 2.11 & 67.5 & 3.96 & 68.33 & 3.80 & $<0.001$ & 0.0003 \\
\hline & 10 & 62.22 & 2.2 & 64.22 & 2.0 & 69 & 3.25 & 69.65 & 3.88 & $<0.001$ & 0.0003 \\
\hline & 12 & 63.54 & 3.0 & 64.27 & 1.4 & 69.5 & 5.44 & 70.75 & 2.81 & 0.04 & 0.0002 \\
\hline
\end{tabular}


classified as skeletal type II, $44 \%$ of these exhibited a normal skull base angle, $48 \%$ exhibited an increased angle and only $2 \%$ decreased angle. Finally, 34 children were classified as skeletal type III, $55 \%$ of these exhibited a normal skull base angle, $38.2 \%$ exhibited an increased angle and $5.9 \%$ exhibited a decreased angle.

When comparing mean values for the cranial base with the skeletal type, a relation was found between an increased length of the skull base and an increased length of the mandibular body for type I subjects $(r=0.435$; $\mathrm{p} \leq 0.001)$ and type III subjects $(\mathrm{r}=0.438 ; \mathrm{p}=0.010)$. As for type II subjects, no correlation was observed between an increased skull base and the mandibular body $(r=0.258 ; p=0.213)$ (Fig. 3 and Table 4 ).

No differences were found between the cranial base length and the skeletal type I, II and III, and stratified by men and women (Fig. 4 and Table 5).

No differences were observed between the skeletal type and the articular angle and the skull base angle. Also, no differences were found between the articular angle and the skull base angle with the gonial angle or the mandibular body length (Table 4).

Type II patients exhibited increased articular angle, which indicates that the position of the glenoid cavity is more posteriorly located and, consequently, so it is the mandibular position; which can be related to the skeletal pattern exhibited.

\section{Discussion}

The anterior cranial base is an important structure for cephalometric diagnosis due to its being considered a stable reference to determine the relationship between

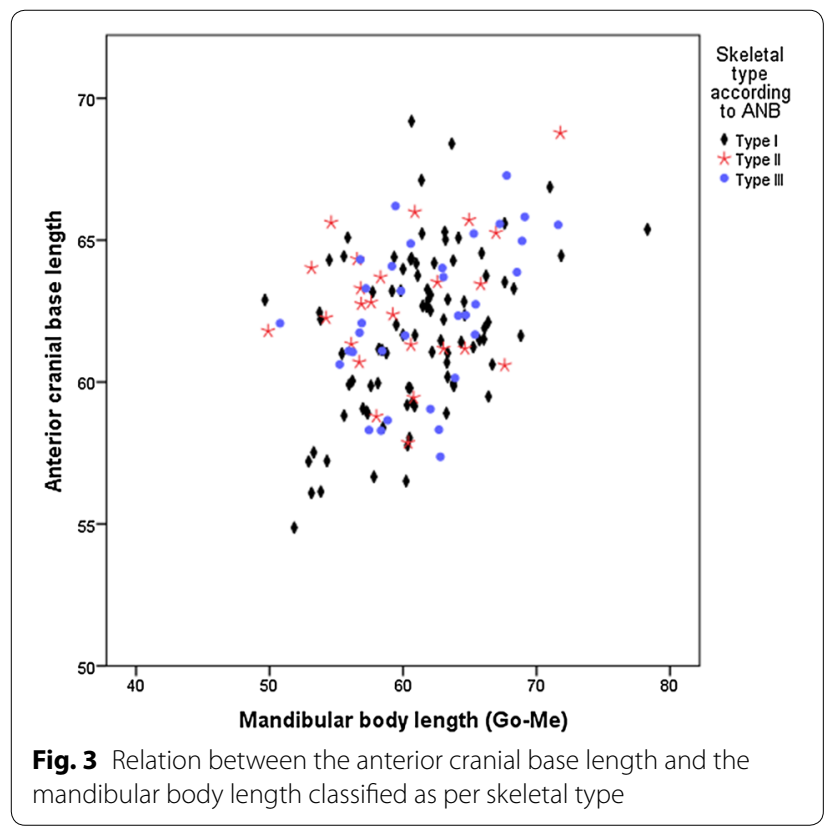

Table 4 Comparison of skeletal type, articular angle and base skull angle with other cephalometric measurements assessed

\begin{tabular}{|c|c|c|c|c|}
\hline & \multirow[t]{2}{*}{$\begin{array}{l}\text { Mean } \\
\text { differences }\end{array}$} & \multicolumn{2}{|c|}{$\begin{array}{l}\mathrm{Cl} 95 \% \text { for mean } \\
\text { differences }\end{array}$} & \multirow[t]{2}{*}{ p value } \\
\hline & & Lower limit & Upper limit & \\
\hline \multicolumn{5}{|c|}{ Skeletal type according to ANB with skull base angle } \\
\hline Type I vs type II & 0.054 & -2.82 & 2.93 & 1.0 \\
\hline Type I vs type III & -0.328 & -2.88 & 2.23 & 1.0 \\
\hline Type II vs type III & -0.382 & -3.73 & 2.96 & 1.0 \\
\hline \multicolumn{5}{|c|}{ Skeletal type according to ANB with anterior cranial base length } \\
\hline Type I vs type I| & -0.97 & -2.46 & 0.52 & 0.349 \\
\hline Type I vs type III & -0.68 & -2.00 & 0.65 & 0.652 \\
\hline Type II vs type III & 0.29 & -1.44 & 2.02 & 1.0 \\
\hline \multicolumn{5}{|c|}{ Articular angle with mandibular body length (Go-Me) } \\
\hline $\begin{array}{l}\text { Normal vs } \\
\text { increased }\end{array}$ & -1.85 & -3.98 & 0.28 & 0.112 \\
\hline $\begin{array}{l}\text { Normal vs } \\
\text { decreased }\end{array}$ & 0.14 & -3.09 & 3.37 & 1.000 \\
\hline $\begin{array}{l}\text { Increased vs } \\
\text { decreased }\end{array}$ & 1.99 & -1.47 & 5.45 & 0.497 \\
\hline \multicolumn{5}{|c|}{ Articular angle with gonial angle (Ar-Go-Me) } \\
\hline $\begin{array}{l}\text { Normal vs } \\
\text { increased }\end{array}$ & 1.26 & -1.16 & 3.69 & 0.625 \\
\hline $\begin{array}{l}\text { Normal vs } \\
\text { decreased }\end{array}$ & 0.16 & -3.51 & 3.83 & 1.0 \\
\hline $\begin{array}{l}\text { Increased vs } \\
\text { decreased }\end{array}$ & -1.10 & -5.04 & 2.83 & 1.0 \\
\hline \multicolumn{5}{|c|}{ Base angle with mandibular body length (Go-Me) } \\
\hline $\begin{array}{l}\text { Normal vs } \\
\text { decreased }\end{array}$ & -0.41 & -3.58 & 2.75 & 1.0 \\
\hline $\begin{array}{l}\text { Normal vs } \\
\text { increased }\end{array}$ & -0.29 & -2.65 & 2.07 & 1.0 \\
\hline $\begin{array}{l}\text { Increased vs } \\
\text { decreased }\end{array}$ & 0.12 & -3.46 & 3.70 & 1.0 \\
\hline \multicolumn{5}{|c|}{ Skull base angle with gonial angle (Ar-Go-Me) } \\
\hline $\begin{array}{l}\text { Normal vs } \\
\text { increased }\end{array}$ & 3.59 & 0.10 & 7.09 & 0.04 \\
\hline $\begin{array}{l}\text { Normal vs } \\
\text { decreased }\end{array}$ & 0.65 & -1.95 & 3.26 & 1.00 \\
\hline $\begin{array}{l}\text { Increased vs } \\
\text { decreased }\end{array}$ & -2.94 & -6.89 & 1.01 & 0.22 \\
\hline
\end{tabular}

the maxilla and the skull (SNA, SNB, SNAr, SNBa), both in the sagittal and vertical dimensions. It also allows establishing positional and rotational diagnosis. Locating the points comprising the posterior cranial base on a lateral cephalic radiography has been controversial. Some authors, including Dhopatkar, Dibbets, Varjanne and Kerr, claim this structure starts at basion point [1, 12-14], while Bjork [8] and Anderson [13] use the articular point, which they consider easier to locate. However, the basion point is more appropriate given its anatomical location, its proximity to the skull base and also because it 


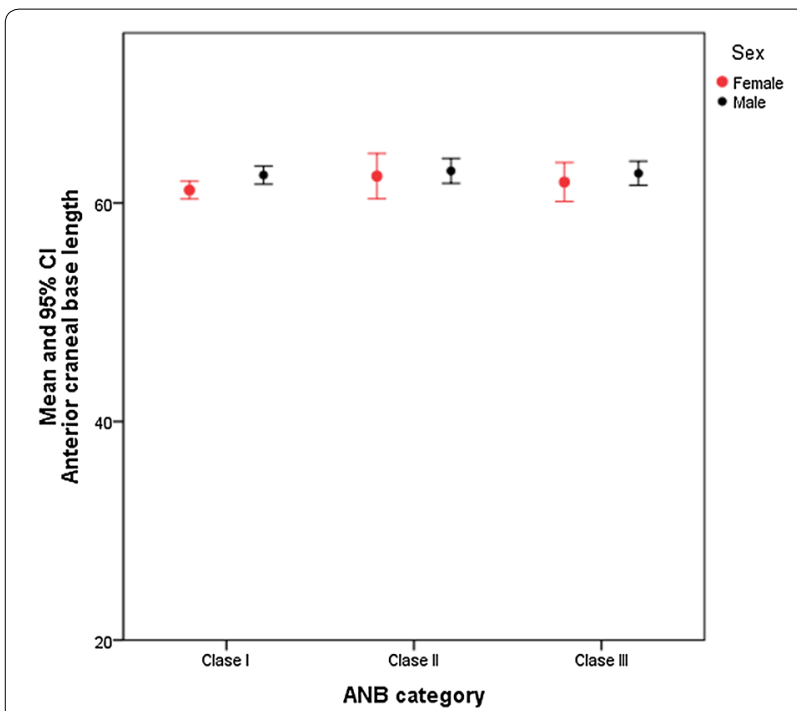

Fig. 4 Relation between the anterior cranial base length and the skeletal type

Table 5 Cephalometric measurements based on the skeletal type, articular angle and skull base angle

\begin{tabular}{|c|c|c|c|c|}
\hline & \multicolumn{2}{|c|}{$\begin{array}{l}\text { Skull base angle } \\
\text { (sella/basion/nasion) }\end{array}$} & \multicolumn{2}{|c|}{$\begin{array}{l}\text { Anterior cranial base } \\
\text { length }\end{array}$} \\
\hline & Mean value & SD & Mean value & SD \\
\hline \multicolumn{5}{|c|}{ ANB skeletal type } \\
\hline Type I & 130.92 & 5.61 & 61.75 & 2.82 \\
\hline Type ॥ & 130.87 & 4.91 & 62.72 & 2.47 \\
\hline \multirow[t]{3}{*}{ Type III } & 131.25 & 4.42 & 62.43 & 2.59 \\
\hline & \multicolumn{2}{|c|}{$\begin{array}{l}\text { Mandibular body } \\
\text { length (Go-Me) }\end{array}$} & \multicolumn{2}{|l|}{$\begin{array}{l}\text { Gonial angle } \\
\text { (Ar-Go-Me) }\end{array}$} \\
\hline & Mean value & SD & Mean value & SD \\
\hline \multicolumn{5}{|c|}{ Articular angle } \\
\hline Normal & 60.47 & 4.65 & 128.86 & 5.75 \\
\hline Increased & 62.32 & 5.00 & 127.59 & 4.47 \\
\hline Decreased & 60.32 & 4.89 & 128.70 & 6.09 \\
\hline \multicolumn{5}{|c|}{ Normal skull base angle (sella/basion/nasion) } \\
\hline Normal & 60.89 & 4.46 & 129.00 & 5.41 \\
\hline Increased & 61.18 & 5.83 & 128.35 & 4.32 \\
\hline Decreased & 61.30 & 5.03 & 125.41 & 6.80 \\
\hline
\end{tabular}

is an anatomical point rather than a cephalometric point $[12,13,15]$. In the present study both points were used to determine the cranial base angle and when compared no significant differences were found between them or in relation to the values yielded by Riolo's study [3].

The cranial base length can be influenced by race $[2,3$, 7]. Most studies determining average lengths based on age have been performed on Caucasian populations $[2$,
3]. It is, thus, important to determine mean cranial base lengths for our population in order to achieve a more accurate sagittal diagnosis of skeletal malocclusion. At the same time, there may be variations in the mean values within a population $[2,3]$. This was demonstrated in the studies by Riolo [3] and Bolton [2], which were carried out in the USA. These authors conclude that there are significant differences (going up to $8 \mathrm{~mm}$ ) for the sellanasion measurement, with Bolton measurement being higher. Similar results have been reported in Colombia in the study by Botero, carried out in Damasco, Antioquia [7]. This study found significant differences with the study by Riolo [3], in which values were lower (up to $8 \mathrm{~mm}$ ) for most dimensions; values being higher for men than for women.

The present study, carried out only with subjects born in Aburrá Valley, found that the cranial base length was significantly higher compared to the study by Riolo [3] $(10 \mathrm{~mm})$ and Botero $(7 \mathrm{~mm})$ [7].

These reported differences, including the one found with the Colombian sample, are attributed both to race variability of each population group and to the genetic admixture it contains. According to some population genetics studies, the population of the metropolitan area of Aburrá Valley has a European ancestral component of $70 \%$, an Amerindian component of $30 \%$ and an African component of $10 \%$, with a deviation of \pm 10 for each percentage [14-16]. Accepting only individuals from the same geographical area can provide certainty of working with individuals who show similar environmental influences and equal genetic ancestry. Having a cranial base size above the average makes the analysis inaccurately result in a maxillary and mandibular protrusion relative to the skull. Furthermore, interpreting cephalometric analysis based upon mean values taken from different population can induced a skeletal misdiagnosis; for example individuals with type I characteristics can be diagnosed as type II when the cranial base length is compared with other population standards given the fact that is bigger than the average [10].

On the other hand, when relating the cranial base length with the mandibular length and the skeletal type (ANB), the results found were similar to those reported by Bjork [12,17] and Kasay [18], who show that there is a relation between mandibular prognathism and the cranial base length. This differs from the results obtained by Wilhelm et al., who found no significant differences between the different skeletal types and the cranial base measurements [19], but is similar with other studies [811] who showed that type III patients have more acute basicranium angle and shorter cranial length. Besides type I patients exhibited a shorter cranial base than the type II and III patients; with no difference between these 
latter groups. This finding is in disagreement with what other studies reported where type III patients exhibited a reduced cranial base length [19]. Cranial base could influence mandibular pragmatism because it determines the antero-posterior location of the condyle related to facial profile [8].

While cranial base flexure can be associated to a specific facial pattern, its role as an etiological factor of sagittal discrepancies is limited and therefore controversial [16]. In the present study, no relationship was found between the cranial base angle and the skeletal type as determined by the ANB measurement [1]. Likewise, no differences were found between the cranial base angle and the type of mandibular rotation. The results of the present study are aligned with the findings reported by Varlela, Dhopatkar and Wilhelm, who concludes that the cranial base angle grows similarly among skeletal types I and II, without becoming more obtuse in the latter type [19-21]. An obtuse cranial base angle causes a downward and backward mandibular rotation, which would favor a type II skeletal relationship. In the present study, no relationship was found between the cranial base angle and the rotation pattern of the subjects (Table 5).

The present study included patients aged 8-12, whereupon the spheno-occipital synchondrosis was fully grown and the cranial base was therefore considered stable. However, Bjork [12] claims the growth of this structure can go up to the age of 10 , from where it increases between 4 and $5 \mathrm{~mm}$ due to anterior apposition between 12 and 20 years old.

The cranial base angle remained relatively stable between the ages of 8 and 12. The variations found (Table 2) may be due to the cross-section nature of the study. In order to analyze changes in the type of structure, it would be necessary to carry out a longitudinal study. The stability reported in this study is aligned with the findings by Anderson [13], which show that the angle alteration occurs from birth to the age of 5 . From this moment to the age of 15 , it remains stable. Therefore, this would demonstrate that the structure observed in the participants of this study can be used as a reference in cephalic serial radiographs.

\section{Conclusion}

The cranial base length influences the measurement of the angles that use it as a reference. Also, since this structure can vary among races, the mean values used must be based on measurements taken in each population.

\section{Abbreviations}

S-N: sella-nasion; S-N-Ba: sella-nasion-basion; S-N-Ar: sella-nasionarticular; SNA: sella-nasion-A point; SNB: sella-nasion-B point; Ar-Go-Me: articular-gonion-menton; Angle ANB: angle formed between point A-point nasion and point $B$.

\section{Authors' contributions}

Conception, design of the work, analysis and interpretation of data: LC, JL, ZVR, PB. Drafting the article: LC, JL. Revising the paper critically for important intellectual content: LC, JL, ZVR, PB. All authors read and approved the final manuscript.

\section{Acknowledgements}

We would like to thank Dr. David Aristizábal, who works at the Centro Radiológico Diagnóstico Oral 3D. Also, we want to thank Dr. Catalina Hincapié for all their valuable assistance in the first stage of this study.

\section{Availability of supporting data}

The database is available in https://mynotebook.labarchives.com/share/pboterom/MjAuOHw2Mzk2MS8xNi9UcmVITm9kZS80MTE1MDkXNTV8NTIuOA== doi: 10.6070/H4542KKS. The data is in anonymized form that complies with data protection/privacy laws.

\section{Competing interests}

The authors declare that they have no competing interests.

\section{Ethics (and consent to participate)}

The study was approved by the Ethics Committee of the Universidad Cooperativa de Colombia, Medellín with the committee's reference number: 0800-0006. A written informed consent from parents and legal guardians was obtained before the beginning of the study.

\section{Funding}

This research was fully funded by Universidad Cooperativa de Colombia, a private University form Colombia, the webpage is: http://www.ucc.edu.co/ (Grant number F31). The funders had no role in study design, data collection and analysis, decision to publish, or preparation of the manuscript, and in the decision to submit the manuscript for publication.

Received: 4 September 2015 Accepted: 2 June 2016

Published online: 14 June 2016

\section{References}

1. Dhopatkar A, Bhatia S, Rock P. An investigation into the relationship between the cranial base angle and malocclusion. Angle Orthod. 2002;72:456-63.

2. Broadbent $\mathrm{BH}$, Broadbent BH, Golden WH. Bolton standards of dentofacial developmental growth. Saint Louis: Mosby; 1975.

3. Riolo M, Moyers R, MacNamara J, Hunter W. An Atlas of craniofacial growth: cephalometric standards from the University school growth study. Craniofacial growth series. Ann Arbor: Michigan; 1979.

4. Zagarra J. A comparative, cephalometric study on the dentofacial patterns of Colombian native Indian and Caucasian of european ancestry. (Master's Thesis). Pittsburg: University of Pittsburgh; 1981.

5. Cardenas G, Lopez O, Lema O, Espinal F, Echeverry L, Velez H (1969) Estudio Cefalometrico De 310 Niños En Una Comunidad Desnutrida: Cephalometric Study in 310 Children from a Malnourished Community. Zeitschrift Für Morphologie Und Anthropologie 61(2):224-38.

6. Palacino DC AM. Estudio cefalometrico en niños con dentición decidua entre los 3 y 5 años de edad del municipio de Envigado (Graduate Thesis). Medellín: Universidad CES; 1996.

7. Botero LM, Ruiz M, Salazar MI, Santa DM, Vélez PA, Villegas N, et al. Longitudinal cephalometric study of growth variability in 55 patients from Damasco Antioquia. CES Odontol. 2009;12:23-7.

8. Sanggamjanavanich S, Sekiya T, Nomura Y, Nakayama T, Hanada N, Nakamaura V. Cranial-base morphology in adults with skeletal class III malocclusion. Am J Orthod. 2014;146(1):82-91.

9. Proff P, Will F, Bokan I, Fanghänel J, Gedrange T. Canial base features in skeletal class III patients. Angle Orthod. 2008;78(3):433-9.

10. Alves P, Muzuchelli J, Patel P, Bolognese A. Cranial base angulation in Brazilian patients seeking orthodontic treatment. J Craniofac Surg. 2008:19(2):334-8. 
11. Chin A, Perry S, Lia Ch, Yang Y. The relationship between the cranial base and jaw base in a Chinese population. Head Face Med. 2014;10:31.

12. Bjork A. Some biological aspects of prognathism and occlusion of the teeth. Acta Odontol Scand. 1950;9:1-40.

13. Anderson D, Popovich F. Relation of cranial base flexure to cranial form and mandibular position. Am J Phys Anthropol. 1983;61:181-7.

14. Bedoya G, Montoya P, García J, Soto I, Bourgeois S, Carvajal L, et al. Admixture dynamics in Hispanics: a shift in the nuclear genetic ancestry of a South American population isolate. Proc Natl Acad Sci USA. 2006;103:7234-9.

15. Carvajal-Carmona LG, Soto ID, Pineda N, Ortíz-Barrientos D, Duque C, Ospina-Duque J, et al. Strong Amerind/white sex bias and a possible Sephardic contribution among the founders of a population in northwest Colombia. Am J Hum Genet. 2000;67:1287-95.

16. Rojas W, Parra MV, Campo O, Caro MA, Lopera JG, Arias W, et al. Genetic make up and structure of Colombian populations by means of uniparental and biparental DNA markers. Am J Phys Anthropol. 2010;143:13-20.
17. Bjork A. The nature of facial prognathism and its relation to normal occlusion of the teeth. Am J Orthod. 1951;37:106-24.

18. Kasai K, Moro T, Kanazawa E, Iwasawa T. Relationship between cranial base and maxillofacial morphology. Eur J Orthod. 1995;17:403-10.

19. Wilhelm B, Beck F, Lidral A, Vig K. A comparison of cranial base growth in Class I and Class II skeletal patterns. Am J Orthod Dentofac Orthop. 2001;119:401-5.

20. Klocke A, Nanda RS, Kahl-Nieke B. Role of cranial base flexure in developing sagittal jaw discrepancies. Am J Orthod Dentofac Orthop. 2002;122:386-91.

21. Varrela J. Early developmental traits in class II malocclusion. Acta Odontol Scand. 1998;56:375-7.

\section{Submit your next manuscript to BioMed Central and we will help you at every step:}

- We accept pre-submission inquiries

- Our selector tool helps you to find the most relevant journal

- We provide round the clock customer support

- Convenient online submission

- Thorough peer review

- Inclusion in PubMed and all major indexing services

- Maximum visibility for your research

Submit your manuscript at www.biomedcentral.com/submit 